\title{
Jejunal monosaccharide, water, and electrolyte transport in patients with chronic pancreatitis
}

\author{
C. A. HELMAN, G. O. BARBEZAT ${ }^{1}$, AND S. BANK \\ From the Gastrointestinal Clinic, Groote Schuur Hospital, and Department of Medicine, University of \\ Cape Town, Cape Town, South Africa
}

SUMMARY Jejunal perfusion studies were performed to assess water, electrolyte, d-xylose, and d-glucose transport in 16 patients with chronic calcific pancreatitis (eight with and eight without steatorrhoea) and in 10 control subjects. The patients with steatorrhoea demonstrated significantly less xylose, water, and electrolyte absorption than patients without steatorrhoea and control subjects, when an isosmotic saline-xylose solution was perfused. On the other hand, when an isosmotic saline-glucose solution was perfused, the patients with steatorrhoea absorbed significantly more glucose, water, and electrolytes than control subjects. Significant correlation was demonstrated between the absorption of xylose as measured by the segmental perfusion technique and the peak serum xylose level during perfusion as well as the five-hour urinary xylose excretion after a $25 \mathrm{~g}$ oral dose of xylose. The xylose absorption measured by small bowel perfusion also correlated significantly with pancreatic juice amylase and trypsin concentrations obtained during a standard pancreatic function test.

Pancreatic steatorrhoea is characterised by the partial or total maldigestion of fat resulting from pancreaticexocrine deficiency (Beck, 1973). Therefore, the capacity of the small bowel to absorb completely digested foodstuffs should not be altered. Bank et al. (1975), however, found diminished absorption of d-xylose in $10 \%$ of 60 patients with pancreatic steatorrhoea subjected to conventional small bowel absorption studies. In view of this finding, small bowel triple-lumen perfusion studies were performed to measure water, electrolyte, $d$-xylose, and glucose absorption in patients with pancreatic insufficiency with and without steatorrhoea.

\section{Methods}

\section{SUBJECTS}

Twenty-six subjects, 13 Caucasians and 13 Mulattos, aged between 20-59 years, were investigated. Informed consent was obtained for all the studies. Sixteen were male patients with grossly abnormal pancreatic function tests and pancreatic calcification on plain abdominal radiographs; of these, eight (mean age 43.8 years, range $32-55$ years) had no

${ }^{1}$ Address for correspondence: Dr G. O. Barbezat, Gastrointestinal Clinic, Groote Schuur Hospital, Observatory, 7925. Cape. South Africa.

Received for publication 6 July 1977 clinical or biochemical evidence of steatorrhoea (mean faecal fat less than $19 \mathrm{mmol} / 24 \mathrm{~h}$ ) and eight (mean age 45.5 years, range $36-56$ years) had overt clinical and biochemical steatorrhoea (mean faecal fat $55.5 \mathrm{mmol} / 24 \mathrm{~h}$, range 28.1 to $103.3 \mathrm{mmol} / 24 \mathrm{~h}$ ) as measured by the method of van der Kamer et al. (1949). The patients with steatorrhoea received pancreatic enzyme replacement until 24 hours before their studies. Ten normal volunteers (four females and six males with a mean age of 39.4 years and a range of 32 to 59 years), with no history of gastrointestinal disease, acted as control subjects.

All the patients with steatorrhoea were insulin dependent diabetics, while the group without steatorrhoea had diabetic glucose tolerance tests and were controlled on diet or oral agents only. Alcohol was considered to be the cause of the pancreatitis in all the patients, but none had clinical evidence of chronic liver disease and all denied alcohol intake for at least three months before the study. The serum alkaline phosphatase, transaminases, and bilirubin concentrations were normal in all subjects. All the subjects had serum albumin levels over $35 \mathrm{~g} \mathrm{litre}^{-1}$ with no significant difference in mean values between the three groups. Jejunal biopsies were not done in these patients, as a previous study from this unit (Bank et al., 1975) showed that 34 of 38 patients with pancreatic steatorrhoea had normal jejunal 
histology while the remaining four had very mild changes on light microscopy.

\section{TECHNIQUE}

\section{Gut perfusion studies}

After an overnight fast of 12 hours the small bowel was intubated with a modified triple-lumen polyvinyl tube (Schmitt et al., 1974) and positioned under fluoroscopic control so that the infusion aperture was just distal to the ligament of Treitz. Openings of the proximal and distal aspiration tubes were located $15 \mathrm{~cm}$ and $45 \mathrm{~cm}$ distal to the infusion point (Cooper et al., 1966). Each patient was perfused with two isosmotic solutions. The first contained d-xylose, 100 mmol $\mathrm{l}^{-1}$ plus sodium chloride $100 \mathrm{mmol}^{-1}$, while the second contained glucose $100 \mathrm{mmol} \mathrm{l}^{-1}$ plus sodium chloride $100 \mathrm{mmol} \mathrm{I}^{-1}$ to bring the total osmolality of each solution to $300 \mathrm{mmol} \mathrm{1}^{-1}$. The solutions contained ${ }^{14} \mathrm{C}$-labelled polyethylene glycol (PEG) $5 \mu \mathrm{Ci} \mathrm{1}^{-1}$ (Miller and Schedl, 1970) as a nonabsorbable volume marker, and were perfused into the jejunum with a peristaltic pump (Harvard Apparatus, Millis, Mass.) at a constant rate of $\mathbf{9 . 2}$ $\mathrm{ml} / \mathrm{min}$. (Unpublished separate studies validated the use of ${ }^{14} \mathrm{C}$-PEG as a marker without carrier PEG in man.) Samples of intestinal contents were collected by manual aspiration at the rate of $1 \mathrm{ml} / \mathrm{min}$ from the proximal and distal aspiration tubes. For each test solution a 45-minute period was allowed for equilibration, followed by a 60 -minute test period. The collections of samples between the proximal and distal aspiration points were staggered by 15 minutes (Whalen et al., 1966). Blood was taken halfhourly for serum sodium, chloride, potassium, and osmolality and 1/4-hourly for blood xylose and glucose.

\section{Urinary xylose excretion}

A five-hour d-xylose urinary excretion test after $25 \mathrm{~g}$ oral load was performed in all subjects (normal value $>5 \mathrm{~g}$ per five hours).

\section{Pancreatic function tests}

These were performed as previously described from this unit (Bank et al., 1963) using secretin (Boots Pure Drug Co., Nottingham, England, 2 units per $\mathrm{kg}$ body weight) and cholecystokinin-pancreozymin (Boots 1.5 units $/ \mathrm{kg}$ body weight) stimulation.

\section{CHEMICAL ANALYSIS}

All determinations were performed in duplicate. Sodium was measured with a flame photometer using an internal lithium standard (Instrumentation Laboratories Inc., Watertown, Mass.), chloride with a chloridometer (Radiometer, Copenhagen), and osmolality by depression of freezing point (Knauer Osmometer, Berlin, West Germany). D-xylose concentrations were measured in protein-free filtrates by the ultramicro-method of Rozental and Tomaszewski (1974). Glucose was measured by the glucose oxidase method. ${ }^{14} \mathrm{C}$-labelled polyethylene glycol was measured in a Packard Tri-carb liquid scintillation spectrometer. One millilitre samples of aspirate were digested with Soluene $350^{1}$, decolourised with isopropanol and hydrogen peroxide $(30-35 \%)$ at $40^{\circ} \mathrm{C}$ and then mixed with Dimilume ${ }^{1}$ scintillator fluid before counting. Net transport of water, sodium chloride, d-xylose, and glucose was determined by standard formulae for the $30 \mathrm{~cm}$ study segment using PEG corrections. Results are expressed as $\mathrm{ml} \mathrm{cm}^{-1}$ $\mathrm{h}^{-1}$ for water, $\mu \mathrm{mol} \mathrm{cm} \mathrm{cm}^{-1} \mathrm{~h}^{-1}$ for electrolytes, and mmol cm $\mathrm{cm}^{-1} \mathrm{~h}^{-1}$ for glucose and d-xylose absorption. Mean results are expressed \pm the standard error of the mean.

During the pancreatic function test the volumes of the duodenal contents aspirated during the 80 minutes of the test was measured. Bicarbonate concentration was measured by acid back titration (normal $>60 \mathrm{mmol} \mathrm{l}^{-1}$ ), amylase by the Pimstone method (1964) (normal $>5 \times 10^{3}$ Pimstone units $\mathrm{ml}^{-1}$ ), and trypsin by a modification of the method described by Schwert and Takenaka (1955) (normal 2000 units $\mathrm{ml}^{-1}$ ).

The statistical significance of the data was evaluated with the unpaired Student's $t$ test.

\section{Results}

Serum electrolytes and osmolality remained unchanged throughout the test.

D-XYLOSE ABSORPTION STUDIES (Fig. 1)

The mean xylose absorption in control subjects (3.33 $\left.\pm 0.17 \mathrm{mmol} \mathrm{cm}^{-1} \mathrm{~h}^{-1}\right)$ and patients with chronic calcific pancreatitis (CCP) without steatorrhoea $\left(3.01 \pm 0.19 \mathrm{mmol} \mathrm{cm}^{-1} \mathrm{~h}^{-1}\right)$ were virtually identical. In contrast, the patients with steatorrhoea absorbed significantly less $\left(1.29 \pm 0.22 \mathrm{mmol} \mathrm{cm}^{-1}\right.$ $\mathrm{h}^{-1}$ ) than controls and patients with CCP without steatorrhoea $(P<0.001)$.

As found with xylose, sodium absorption was greatly reduced in patients with CCPand steatorrhoea $\left(71.8 \pm 20.3 \mu \mathrm{mol} \mathrm{cm}^{-1} \mathrm{~h}^{-1}\right)$ when compared with their counterparts without steatorrhoea $(164 \cdot 2 \pm$ $\left.13.4 \mu \mathrm{mol} \mathrm{cm}^{-1} \mathrm{~h}^{-1}\right)$ and controls $(191.1 \pm 10 \cdot 4$ $\mu$ mol $\mathrm{cm}^{-1} \mathrm{~h}^{-1}$ ). This difference between steatorrhoeic patients and the other two groups is highly significant $(P<0.001)$, whereas there is no significant difference between controls and the patients without

${ }^{1}$ Obtained from Packard Instrument Company. 


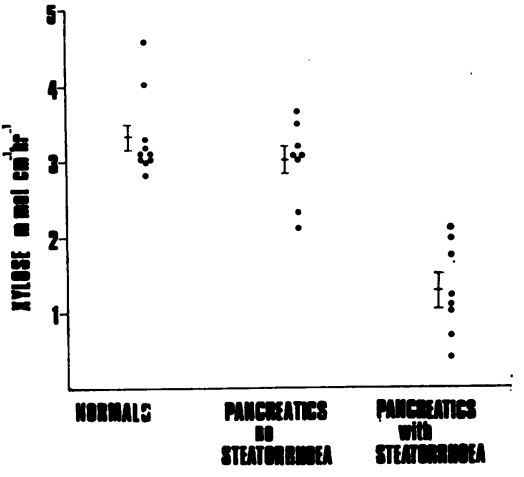

Fig. 1 Absorption of $d$-xylose from the jejunum of normal controls and patients with calcific pancreatitis without and with steatorrhoea. Bar represents mean \pm SEM. Patients with steatorrhoea absorbed significantly less than both other groups $(\mathrm{P}<0.001)$.

steatorrhoea. Chloride and water fluxes predictably closely paralleled those of sodium and d-xylose.

During the five-hour test period of the urinary d-xylose excretion test, the control subjects excreted a mean of $9.6 \mathrm{~g} \mathrm{~d}$-xylose with a range of 6.6 to $20 \mathrm{~g}$. The pancreatic patients without steatorrhoea excreted a mean of $9.9 \mathrm{~g}$ with a range of 5.8 to $14.6 \mathrm{~g}$, while those with steatorrhoea excreted a mean of 4.7 $\mathrm{g}$ with a range of 1.2 to $8.5 \mathrm{~g}$. The difference between the two groups of pancreatic patients was not statistically significant $(P>0 \cdot 1)$. There was, however, a significant difference between controls and those with steatorrhoea $(P<0.01)$.

There was a highly significant correlation between the results of the routine oral $(25 \mathrm{~g})$ xylose loading test and xylose absorption using the triple-lumen tube $(r=0.75 ; \mathrm{P}<0.001)$. The xylose absorption measured by small bowel perfusion also correlated significantly with peak serumd-xylose levels measured during the perfusion $(r=0.95 ; \mathrm{P}<0.001)$. Similarly, there was a positive correlation between xylose absorption as measured by gut perfusion and the stimulated pancreatic juice amylase $(r=0.84$; $\mathbf{P}<0.001)$ and trypsin $(r=0.78 ; \mathrm{P}<0.001)$ concentrations.

GLUCOSE ABSORPTION STUdies (Fig. 2)

Jejunal perfusion with the isosmotic glucose solution in control subjects showed glucose absorption of $4.44 \pm 0.19 \mathrm{mmol} \mathrm{cm}^{-1} \mathrm{~h}^{-1}$. The patients with CCP without steatorrhoea absorbed $4.46 \pm 0.51 \mathrm{mmol}$ $\mathrm{cm}^{-1} \mathrm{~h}^{-1}$, whereas the patients with steatorrhoea absorbed $5.32 \pm 0.19 \mathrm{mmol} \mathrm{cm}^{-1} \mathrm{~h}^{-1}$, which is significantly more than controls $(P<0.01)$ but not significantly different from patients without steatorrhoea $(P>0 \cdot 1)$.

Sodium absorption was $424.1 \pm 90.04 \mu \mathrm{mol} \mathrm{cm}^{-1}$ $\mathrm{h}^{-1}$ in controls, $467.6 \pm 55.51 \mu \mathrm{mol} \mathrm{cm} \mathrm{cm}^{-1} \mathrm{~h}^{-1}$ in patients without steatorrhoea, and 517.9 \pm 25.57 $\mu \mathrm{mol} \mathrm{cm}{ }^{-1} \mathrm{~h}^{-1}$ in patients with steatorrhoea. Chloride and water absorption followed the same pattern as sodium, all being significantly increased in patients with $\mathrm{CCP}$ and steatorrhoea $(\mathrm{P}<0.01)$ when compared with controls and patients with CCP without steatorrhoea.

\section{Discussion}

This study has shown that patients with pancreatic steatorrhoea have a highly significant decrease in xylose absorption by the jejunum as compared with normal controls and subjects with calcific pancreatitis without steatorrhoea. The pathogenesis of this decreased absorption of xylose is not apparent. Alcohol-induced damage to the small bowel mucosa is unlikely, as both groups of patients with pancreatitis had inbibed similar quantities of alcohol.

The xylose malabsorption would not appear to be dependent on morphological changes in the jejunal mucosa in patients with pancreatic steatorrhoea. Studies from India have, however, shown mild changes, mainly increased villous width (Madanagopalan et al., 1965). On the other hand, Bank et al. (1975) found 34 of 38 jejunal biopsies to be normal, the remaining four showing only minor changes, while Shimoda et al. (1974) found the jejunal mucosa of four patients with pancreatic steatorrhoea to be normal by electron microscopy. Diabetic neuropathy of the gastrointestinal tract may

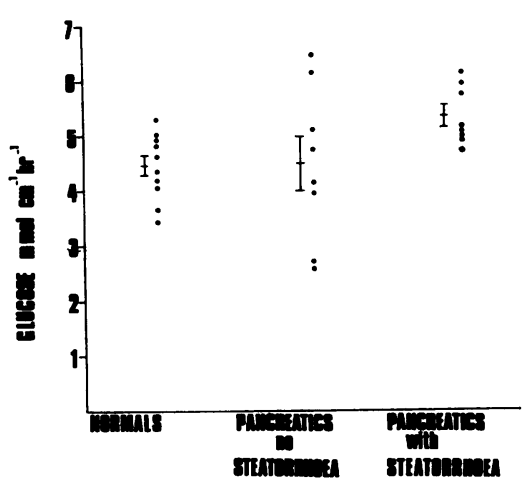

Fig. 2 Absorption of d-glucose from the jejunum of normal controls and patients with calcific pancreatitis without and with steatorrhoea. Bar represents mean $\pm S E M$. Patients with steatorrhoea absorbed significantly more than control subjects $(\mathrm{P}<0.01)$. 
produce diarrhoea but these patients usually have peripheral neuropathy, nephropathy as well as retinopathy, and xylose absorption is normal in these patients (Katz and Spiro, 1966). None of our patients showed any of these findings. The positive correlation between pancreatic function and xylose absorption in our patients poses the interesting possibility that the exocrine secretion of the pancreas may have a part to play in the absorptive function of the small bowel.

The increased glucose absorption found in our patients with insulin dependent diabetes and steatorrhoea is also found in genetic diabetes (Vinnik et al., 1965) and this increased glucose absorption was not altered by insulin. As expected, water and electrolyte absorption followed that of glucose in the present study (Sladen and Dawson, 1969). On the other hand, Moshal (1973) found an inexplicable decreased glucose absorption in spite of increased sodium and water absorption in pancreatic diabetics. The mechanism of enhanced intestinal absorption of glucose in diabetics is unknown. Some functional change in the small bowel in the diabetic state has been suggested (Varma and Banerjee, 1963). The increased glucose absorption may be dependent on the severity of the endocrine abnormality, as it was found only in our patients with insulin dependent diabetes and not in those with diabetes treated by diet or oral agents alone. This has a possible experimental counterpart, Crane (1961) showing that the rate of intestinal glucose transport did not increase immediately after injection of alloxan into rats, but increased progressively over several days in association with the development of diabetes. It remains unclear why glucose absorption should be increased while xylose absorption is decreased in patients with pancreatic steatorrhoea.

This work was supported by grants from the South African Medical Research Council. Dr C. Helman was in receipt of a MRC Research fellowship. The authors thank Mrs T. Strano, Mrs I. Kramer, and Mrs L. Petersen for excellent technical assistance and Professor E. Dowdle for isotope counting facilities.

\section{References}

Bank, S., Marks, I. N., Moshal, M. G., Efron, G., and Silber, R. (1963). The pancreatic-function test-method and normal values. South African Medical Journal, 37, 10611066.

Bank, S., Marks, I. N., and Novis, B. H. (1975). Small bowel structure and function in pancreatic steatorrhoea. Mount Sinai Journal of Medicine, 42, 552-564.

Beck, I. T. (1973). The role of pancreatic enzymes in digestion. American Journal of Clinical Nutrition, 26, 311-325.

Cooper, H., Levitan, R., Fordtran, J. S., and Ingelfinger, F. J. (1966). A method for studying absorption of water and solute from the human small intestine. Gastroenterology, 50, 1-7.

Crane, R. K. (1961). An effect of alloxan-diabetes on the active transport of sugars by rat small intestine in vitro. Biochemical and Biophysical Research Communications, 4, 436-440.

Kamer, J. H. van der, Ten Bokkel Huinink, H., and Weyers, H. A. (1949). Rapid method for the determination of fat in feces. Journal of Biological Chemistry, 177, 347-355.

Katz, L. A., and Spiro, H. M. (1966). Gastrointestinal manifestations of diabetes. New England Journal of Medicine, 275, 1350-1361.

Madanagopalan, N., Shiner, M., and Rowe, B. (1965). Measurements of small intestinal mucosa obtained by peroral biopsy. American Journal of Medicine, 38, 42-53.

Miller, D. L., and Schedl, H. P. (1970). Total recovery studies of non-absorbable indicators in the rat small intestine. Gastroenterology, 58, 40-46.

Moshal, M. G. (1973). A study of chronic pancreatitis in Natal. Digestion, 9, 438-446.

Pimstone, N. R. (1964). A study of the starch-iodine complex: a modified colorimetric micro determination of amylase in biologic fluids. Clinical Chemistry, 10, 891-906.

Rozental, M., and Tomaszewski, L. (1974). A new simple ultramicromethod for the determination of d-xylose in blood and urine. Clinica Chimica Acta, 50, 311-317.

Schmitt, M. G., Jr, Wood, C. M., and Soergel, K. H. (1974). A method for rapid placing of small intestinal perfusion tubes. Gut, 15, 227-228.

Schwert, G. W., and Takenaka, Y. (1955). A spectrophotometric determination of trypsin and chymotrypsin. Biochimica et Biophysica Acta, 16, 570-575.

Shimoda, S. S:, Saunders, D. R., Schuffler, M. D., andl Leinbach, G. L. (1974). Electron microscopy of small! intestinal mucosa in pancreatic insufficiency. Gastroenterology, 67, 19-27.

Sladen, G. E., and Dawson, A. M. (1969). Interrelationships between the absorptions of glucose, sodium and water by the normal human jejunum. Clinical Science, 36, 119-132.

Varma, S. D., and Banerjee, S. (1963). Intestinal absorption of glucose in normal and diabetic rats: the effect of ethylenediamine-tetra-acetate (EDTA). Indian Journal of Medical Research, 51, 507-511.

Vinnik, I. E., Kern, F., Jr, and Sussman, K. E. (1965). The effect of diabetes mellitus and insulin on glucose absorption by the small intestine in man. Journal of Laboratory and Clinical Medicine, 66, 131-136.

Whalen, G. E., Harris, J. A., Geenen, J. E., and Soergel, K. H. (1966). Sodium and water absorption from the human small intestine: the accuracy of the perfusion method. Gastroenterology, 51, 975-984. 